\title{
A Cognition-based View of Decision Processes in Complex Social- Ecological Systems
}

\author{
$\underline{\text { Kathi K. Beratan }}^{1}$
}

\begin{abstract}
This synthesis paper is intended to provide an overview of individual and collective decisionmaking processes that might serve as a theoretical foundation for a complexity-based approach to environmental policy design and natural resource management planning. Human activities are the primary drivers of change in the Earth's biosphere today, so efforts to shift the trajectory of social-ecological systems must focus on changes in individual and collective human behavior. Recent advances in understanding the biological basis of thought and memory offer insights of use in designing management and planning processes. The human brain has evolved ways of dealing with complexity and uncertainty, and is particularly attuned to social information. Changes in an individual's schemas, reflecting changes in the patterns of neural connections that are activated by particular stimuli, occur primarily through nonconsious processes in response to experiential learning during repeated exposure to novel situations, ideas, and relationships. Discourse is an important mechanism for schema modification, and thus for behavior change. Through discourse, groups of people construct a shared story-a collective model-that is useful for predicting likely outcomes of actions and events. In effect, good stories are models that filter and organize distributed knowledge about complex situations and relationships in ways that are readily absorbed by human cognitive processes. The importance of discourse supports the view that collaborative approaches are needed to effectively deal with environmental problems and natural resource management challenges. Methods derived from the field of mediation and dispute resolution can help us take advantage of the distinctly human ability to deal with complexity and uncertainty. This cognitive view of decision making supports fundamental elements of resilience management and adaptive co-management, including fostering social learning through the involvement of a broad range of stakeholders, and building trust and increasing links among governance organizations.
\end{abstract}

Key Words: cognition; complex social-ecological systems; cultural change; decision making; discourse; natural resource management; schemas

\section{INTRODUCTION}

Human activities are the primary drivers of change in the Earth's biosphere today. Thus, individual and collective human behavior change will inevitably be the focus of efforts to respond to environmental problems. Design of policies and management actions that can effectively shift the trajectory of social-ecological systems toward more desirable directions requires an in-depth understanding of how real people make decisions, and how they interact with each other and with their natural environment (Lal et al. 2001, Grothmann and Patt 2005).
Ecology has been a logical parent field for the resilience perspective, with its focus on uncertainty, surprise, and the importance of cross-scale interactions; ecology is itself a systems science, based on careful study both of individual species and of the interactions among species. Only recently have similarly integrative, cross-scale fields of study begun to emerge within the human-centered sciences. Traditionally, study of the individual and the collective in human systems has been separated by disciplinary barriers that have made it difficult to deal with the extreme complexity of real-world systems that include human actors within a cultural context. In general, the social sciences have tended not to fully consider the implications of complexity

${ }^{1}$ Department of Forestry and Environmental Resources, North Carolina State University 
on human actions and interaction, and as a result, the simplifying assumptions commonly employed have limited the relevance of research results to realworld problem-solving efforts.

In recent years, there has been a rich exploration in the human system sciences of the origins and meaning of thought, behavior, and culture. Research in young fields, such as cognitive anthropology and social neuroscience, that link micro- and macrolevels of analysis is starting to shift the academic conversation away from how people "ought" to make decisions (e.g., rational decision models) toward how the human brain actually "does" function, both on its own and in a social context. As Siegel (2001;p. 85) notes, application of complexity principles "to the layers of systems, from neural circuits to interpersonal relationships, can provide useful insights into the bridges across these levels of analysis." The early products of these integrative studies show great promise for enhancing the effectiveness of practice in applied fields, such as natural resource management.

This synthesis paper integrates findings from current research in several human systems science fields into a broad conceptualization of individual and collective decision-making processes. The intent of this transdisciplinary compilation is to provide a theoretical foundation for understanding cross-scale human system dynamics related to behavioral and cultural change and development of a complexity-based approach to policy design and management planning that is practical and effective in real-world settings.

\section{COGNITION AND DECISION MAKING}

\section{Cognitive Processes}

In real-world decision processes, policy and management decisions emerge from countless complexly interlinked decisions made by individuals; any single decision process ultimately begins with a single human brain responding to some sensory input (information). Therefore, this discussion begins by exploring human cognitive processes-how the human brain absorbs information, recognizes and frames problematic situations, and chooses appropriate responses. There is still a significant knowledge gap between what we know about the biology of the brain and the emergent products of brain activity, including memory and decision making. However, what has been learned about the mind provides significant insights into dynamics of individual and collective behavior.

The human mind is a complex adaptive system. Properties at one observational level, such as thoughts and memories, are emergent from dynamic interactions among lower-level entities, such as the neurons that are the building blocks of cognitive architecture. Neuroscience research has shown that the biological basis of thoughts and memories are neuronal circuits, patterns of connections among neurons. Although the details of this process are not yet clear, cognitive neuroscientists generally agree that patterns of firings of neurons create the experience of mind (Siegel 2001). As yet, the exact mechanisms by which neuronal circuits are created, accessed, modified, and integrated into dynamic cognitive processes and products is not fully understood. Cognitive processes more complex than those within the sensory and motor systems appear to entail multiple neural operations mediated by distributed, interacting neuronal circuits. Much of what humans do cognitively, notably including social processing, involves use of many integrated neural substrates for attention, sensory and perceptual processing, motivation, memory access and associative linkage, expectations, decision making, and response processes (Berntson 2006).

An enormous amount has been published in the past decade about the "geography" of the brain and the neural substrate of behavior. The details of this geography - the localization of various aspects of cognitive function within the brain - are beyond the scope of this paper. The basic observations that are of relevance here are that experience involves the activation of interconnected neurons, and that thoughts consist of dynamic patterns of connections among neurons.

Memory is the way in which experience is encoded in the brain and shapes present and future functioning (McClelland 1998, Milner et al. 1998). There appear to be two distinct types or mechanisms of memory: implicit and explicit. Implicit memory includes emotional, behavioral, perceptual, and perhaps bodily (somatosensory) forms of memory (Siegal 2001). Implicit memory slowly learns general regularities from repeated experiences (Smith and DeCoster 2000). When implicit memories are activated, they do not have an internal sensation that something is being recalled. Thus, 
implicit memories directly shape our here-and-now experiences without clues to their origins from past events. Explicit memory (Bauer 1996) includes two major forms: factual (semantic) and autobiographical (episodic) (Tulving et al. 1994). For both types of explicit memory, recollection is associated with an internal sensation of "I am recalling something now" (Siegel 2000). Both implicit and explicit memories are stored as patterns of neural connections; whenever one part of the pattern is activated (by sensory input, for instance), activation spreads through the whole interconnected set of neurons. These connections are strengthened with use.

This basic understanding of mind and memory can be linked to individual decision making through conceptualizations of cognitive processing. Most researchers posit some variant of a "dual process model" (Chaiken and Trope 1999) of thought and cognition, in which human thought processes involve two parallel systems of reasoning (Sloman 1996) or processing modes (Smith and DeCoster 2000): a rapid "nonconscious" (or preconscious) mode and a more effortful "conscious" mode. Nonconscious processing is effortless and automatic. It makes use of implicit memory (Smith and DeCoster 2000), and thus contextualizes the current situation in light of background beliefs and knowledge that reflect the learning history of the individual (Evans et al. 2003). Actions taken without conscious thought are, in effect, based on the assumption that the results of a given action or event in a particular situation will be very similar to the results of similar actions or events in similar situations encountered in the past.

Conscious processes are mental acts of which we are aware, that we intend (i.e., that we start by an act of will), that require effort, and that we can control (i.e., we can stop them and go on to something else if we choose) (Bargh and Chartrand 1999). Conscious thought is subjectively effortful, requiring attention, motivation, and available cognitive capacity (Smith and DeCoster 2000). Conscious processing is valuable because it permits us to deal with novelty, and to develop new strategies for dealing with long-standing problems. Reliance on nonconscious routine is fast and efficient, but sacrifices flexibility and creativity, and so consciousness is useful for those tasks in which we must preserve flexibility, and for which we cannot rely on routine (Reisberg 1997). Hertwig and Todd (2003) point out that humans are uniquely able to set aside mental shortcuts and engage in extensive cognition, calculation, and planning.

Most of the activity that goes on in our brains does not require the scarce resource of conscious thought, and so approximately $98 \%$ of what the brain does is done outside of conscious awareness and guidance (Bargh and Chartrand 1999, Gazzaniga 2002). Even conscious thought has a significant nonconscious component; for example, experimental findings indicate that overt (conscious) reasoning is preceded by a nonconscious biasing step (Bechara et al. 2002). Because so few cognitive events rise to the level of consciousness, we are usually unaware of the process of our thoughts; we are instead aware only of the products that result from that process (Reisberg 1997). An example of this is commonly observable during problem definition in most complex decision situations. The decision makers assume that they know what the problem is, and seldom examine that assumption in any depth. They are not aware of the nonconscious processing through which their brains evaluated accumulating information and defined a set of conditions as constituting a problem that needed to be addressed by conscious cognitive processes.

\section{The Cognitive Basis of Behavior}

Decision making is usually described as a process of selecting from a set of alternative responses. In this context, it is tempting to think of the nonconscious mind as constantly testing one particular type of "if-then" hypothesis: "if the current situation is sufficiently similar to this particular group of past situations, then action A will produce result B." If no clear answer emerges (e.g., in situations for which no sufficiently similar past experiences can be identified), the problem will get passed along to the conscious mind. Through conscious processing, we develop and test situationspecific hypotheses, which involves identification and characterization of the potential alternatives, followed by some sort of comparison among them (Loewenstein 2001, Becker 2004). The results of conscious processing are then integrated into our experiential knowledge, and thus become available for future use by the nonconscious mind.

This characterization makes sense, and seems to neatly integrate cognitive processes with boundedly rational views of decision making. However, in light of neuroscience revelations about the neural 
substrates of thought and behavior, this view of decision making seems not to capture the actual cognitive mechanisms at work. It describes decision making as a linear process, with problem definition followed by delineation of alternatives, followed by choice of response. Instead, it appears that our thought processes operate through a decidedly nonlinear process of emergence.

Given the mechanisms by which memories are stored (as patterns of neural connections), it seems likely that an early step in the cognitive decision process is activation of a pattern of neurons that represents a desired outcome (or an outcome to be avoided). That pattern of active neural connections would then interact with patterns representing perceptions of current conditions to trigger a cascade of neural activity, shaped by connections formed through past experience, from which a pattern emerges that guides actions. In other words, rather than the brain compiling a competing set of alternative actions, a single pathway (a linked set of actions) that is likely to lead to the desired outcome (or that is likely to avoid the undesired outcome) emerges from nonconscious cognitive processing. We "know" how to get there, without being aware of how we arrived at that knowledge. If called upon to explain, we may then use conscious processing to construct a logical rationale for the decision we have made and, perhaps, examine the validity of that decision.

Our brains contain an abundance of potentially relevant stored patterns formed as a result of past experience, and how we respond in a particular situation is largely determined by which neural pattern is activated. Priming effects are key in this nonconscious selection process: all sensory input, including verbal and nonverbal human communication, activates particular patterns of neural connections. This activity primes neural pathways that are peripherally linked to the active pathways, making it more likely that these peripheral pathways will be activated by subsequent input. In turn, some connections may remain active for a longer time than others due to peripheral links to subsequent patterns. In other words, contingency has a strong impact on the emergent pattern.

Based on this view of cognitive processing, it is not surprising that decision researchers have found that how a question is asked and how the options are described strongly affects preferences, even when the descriptions or presentations are normatively equivalent (Tversky and Kahneman 1986). It is likely that many "heuristics," rather than being logical decision rules (even "boundedly rationale" ones), are actually patterns of neural connections that retain a record of general regularities encountered through experience.

\section{Schemas and Behavior Change}

The term "schema" will be used here to refer to cognitively accessible representations of past experience, which are stored as linked neuronal circuits. This usage follows Harris's (1994) description of schemas as the dynamic, cognitive knowledge structures regarding specific concepts, entities, and events used by individuals to encode and represent incoming information efficiently. Schemas are typically conceptualized as subjective theories derived from one's experiences about how the world operates (Markus and Zajonc 1985) that guide perception, memory, and inference (Fiske and Taylor 1984). In this conceptualization, schemas direct information acquisition and processing, in addition to being knowledge repositories (Harris 1994).

Schemas provide the templates for an individual's routine behaviors. Thus, a change in behavior must entail a change in existing schemas or development of new schemas. Major shifts in viewpoint and restructuring of schemas require conscious thought and effort. This level of effort will only be expended in response to situations that are identified by nonconscious cognitive processes as being high priority. It is important to note that the critical variable in this decision process is not the severity of the problem situation, but instead the individual's perception of the situation.

An individual will not begin to seek a solution to a problem situation unless and until he or she becomes aware of it. In the context of cognitive processes, awareness results when a situation is passed from nonconscious to conscious processing in response to unexpected conditions and events. Minor discrepancies between expected and observed conditions commonly can be dealt with simply through a change in how we categorize the situation, which will automatically trigger an abrupt shift in which schemas are activated (Loewenstein 2001). For example, people have multiple ways of thinking about forested or undeveloped land. An individual may generally favor development in his or her 
community because past experience has shown that it leads to rising property values. However, signs of degradation of a stream that the individual sees frequently may shift his or her viewpoint from "development leads to higher property values" to "this development is harming a resource that I value," indicating a shift in categorization. Such shifts in referent schemas are typical of NIMBY ("not in my back yard") situations.

If none of the individual's schemas can adequately explain the perceived discrepancy between expectations and observations, and if the discrepancy sufficiently impairs nonconscious direction of action, conscious processing will be engaged and the individual will become "aware" of the situation. A discrepancy that appears abruptly is more likely to trigger a transition to conscious awareness than will one that develops incrementally; likewise, multiple discrepancies clustered in time, whether causally linked or simply coincidental, are more likely to trigger awareness. Therefore, focusing or triggering events (Birkland 1997) can play an important role in the transition to awareness, particularly when those events are perceived as being related manifestations of a larger, longertime-scale process. For example, the occurrence of a number of extreme weather events in the United States during the past several years (e.g., multiple destructive hurricanes hitting the Gulf Coast and Florida, and severe drought and destructive wildfires in the southwestern United States) have triggered increased awareness of and concern about global climate change.

Focusing events not only capture our attention; they can have a direct impact on the schemas that guide our behavior. Stress hormone systems activated by emotional situations enhance long-term memory formation (Cahill and McGaugh 1998), so that a person experiencing stress can learn based on a single exposure. Thus, the "window of opportunity" opened by a focusing event is tied to the biology of the mind. In contrast, repeated exposure to new ideas over time is required in non-stressful situations before those ideas are "learned"consolidated into long-term memory and integrated into schemas-and thus can influence nonconscious processing (Dagenbach et al. 1990, Bargh and Chartrand 1999). For this reason, a single experience or exposure to decontextualized information (e.g., an information sheet mass-mailed from a government agency) is unlikely to have any long-term impact on behavior.

\section{Cognitive Strategies for Dealing with Complexity}

At both the individual and collective levels, coping with complexity requires the ability to strategically filter the vast quantity of available information, and to integrate the key information into some sort of implicit or explicit predictive model. We are constantly bombarded by an effectively infinite amount of sensory information from the environment. In order to make even the simplest decision at a nonconscious level, our brains must selectively attend to only a limited subset of the available information. Selective attention and focus become increasingly important as the complexity of the decision situation increases. Human cognition appears to be a highly effective adaptation to the challenge of dealing with complexity, and strategic filtering is a particularly important and welldeveloped competency. Our brains are exceptionally adept at plucking a limited array of critical information from the incoming flood of sensory input (see Evans et al. 2003), with filtering occurring both during perception and thought; sensation, attention, conscious processing, and memory are all highly selective (Kenrick et al. 2003). Schemas may serve as filters in part of this process.

The brain's strategic filtering strategies are the likely source of many of the "cognitive biases" noted by decision researchers. For example, the human tendency to discount the future can be related to the observation that natural system processes operate at a wide range of time scales, whereas the temporal range of human perception and optimal cognitive function is narrow. One benefit of our narrow temporal range of perception is that it serves as a filter, limiting the amount of information that we need to consider. In other words, limiting observations to a particular scalar range allowed our ancestors to focus on the natural system elements and processes most critical for survival. Such temporal focusing does not require that we have some sort of module or "fixed" program that controls what we attend to. Instead, experience may play a major role by shaping the patterns of neural connections through which we remember and think, and through which we filter incoming information. What we experience is heavily influenced by the capabilities of our sensory apparatus - we can see a dog, but cannot see a bacterium without magnification, and have trouble seeing the full extent of a forest that we are in the middle of. Evolution and natural selection shaped and fine- 
tuned our sensory apparatus, so it is reasonable to assume that we are most sensitive to stimuli that occur within the range of temporal and spatial scales that are most relevant to individual and small group survival. Nonconscious decision making, which is guided by past experience, will naturally favor processes operating within our focal temporal range, thus "discounting" the future. This does not mean that we are incapable of considering longertime-scale processes and consequences in decision making, just that specific conscious effort is needed to do so.

Specialization-the division of cognitive labor among a group of people-is another way in which humans manage complexity. The more that an individual knows about a particular subject, the more adept he or she will be in quickly identifying key information and how that information relates to other information. No individual can know everything; therefore, specialization serves as a collective strategy for increasing the usefulness of the implicit and explicit predictive models that form the cognitive basis for action. Everyone involved with a decision process - technical experts, formal decision makers, and stakeholders - has specialized knowledge about some part or aspect of the complex social-ecological system in question; none has anything approaching a complete understanding of the system. Each individual's knowledge represents a partial system description that is, in effect, a conceptual model of the dynamics of a particular part or aspect of the system. Individually, each of us has experience with only a small part of the system of interest, whereas collectively we have experience with most of the system. Each individual's sub-model contributes to a greater or lesser degree to a collective system model, expressed in part as cultural norms and collective expectations. How well the sub-models are integrated and coordinated is a significant factor determining the effectiveness of collective decisions and actions. Integration and coordination occur primarily by means of interpersonal interactions, and thus governance systems that provide abundant opportunities for face-to-face interactions among both those making and affected by decisions should be more effective over the long run, particularly in times marked by change.

Given the complexity of the social-ecological systems we are part of, similar specialization and division of labor at social scales is both necessary and unavoidable. For this reason, fragmentation of management responsibility is a necessary and unavoidable societal-scale response to complexity. This statement is in subtle contrast to the more common view of fragmentation solely as a barrier to progress in solving complex societal problems (e. g., Bardach 1998, Yaffee 1997), and relates to concepts of "networked governance" (e.g., Ostrom 1990, Jackson and Stainsby 2000, Blatter 2003). An important consequence of the functional necessity of fragmentation is that collaboration is essential for effective governance.

\section{Discourse and Cultural Change}

Social interaction is an important component of individual decision making. Once we become aware of a problematic situation, our conscious minds will pose questions related to whether or not to act, and what form that action might take. Because each individual is embedded within a complex social structure, information about human actors, both individuals and groups, is particularly important for predicting the likely outcomes of actions, and thus social knowledge generally is much more important to accurate prediction of the outcomes of actions than are scientific facts regarding biophysical processes. Even in relatively simple decision situations, social consequences (how others will act, what others will think of our reaction) are a central consideration. In more challenging situations, where the need for action and the potential consequences of action or inaction are uncertain, an individual is likely to try to reduce that uncertainty by seeking additional knowledge through discussions with a selected group of friends and relatives, and with other people who are perceived to have relevant expertise (Rogers 2003). The further a potential action deviates from established practice, the more extensive and involved the discussion will be.

As noted previously, knowledge about a given system's structure and behavior is distributed among a large number of organizations and individuals. No one individual (Olsson et al. 2004) or organization can fully understand, and no one viewpoint can adequately capture, the dynamic behavior of a social-ecological system. Most of this distributed knowledge, especially social knowledge, is tacit rather than explicit, acquired through practical experience in the relevant context. Tacit 
knowledge is personal and contextual, and transfer from one person to another requires social interaction-discourse-among individuals (Lam 2000).

Any significant change in the trajectory of a socialecological system necessarily involves cultural change, and discourse is central to the process of cultural change. Culture is emergent from the complex, multi-scale web of social interactions, and is expressed as norms and assumptions; in other words, cultures integrate individual experiences and insights. In this sense, culture can be thought of as a commonly held set of schemas from which collective expectations of the future are derived. Cultural evolution can only occur when new values and assumptions are introduced and accepted in a way that integrates them with existing ones (Keyton 2005). Thus, cultural evolution occurs as part of a feedback loop in which changes in collective schemas both reflect and influence modifications of individuals' schemas. As Hutchins (1994; p. 354) argues, "Culture is an adaptive process that accumulates partial solutions to frequently encountered problems."

Collective efforts to direct cultural change require that key individuals and groups cooperate and work together toward a common or complementary set of goals and objectives. Cooperation requires both shared understanding and trust. Based on the cognitive processes described above, reciprocal trust implies that the actions of both parties are guided by compatible (but not identical) schemas regarding cause and effect. When we trust someone, we believe that we understand his or her motives and objectives, and that those motives and objectives are compatible with (not necessarily the same as) our own (i.e., I believe that you getting what you want helps me get what I want, or at least that it doesn't interfere). Predictability is a critical element of trust: we trust that we understand someone's motives and objectives, and therefore we trust that we know how they will respond in a given circumstance. Thus, an important effect of trust is that it reduces uncertainty and effectively simplifies complexity.

Shared understanding and trust are built through many personal interactions over time. We learn about people's views and behavior through conversation, and by having opportunities to compare what they say (verbally and non-verbally) with their actions. In other words, we modify our schemas relating to other people through repeated experience of interaction with them. Therefore, discourse is an essential component of collective decision making and management activities. Discourse has been recognized as being central to the capacity for a single organization to adapt to changing conditions (Addleson 1996, Dooley 1997); it is even more important in efforts to improve conditions within a broader socialecological system.

Humans have developed a sophisticated means of efficiently communicating complex social information: storytelling. Narrative stories provide explanations of how the world works (Stone 2002); a good story shows and explains the connections between the people, places, events, and things that are significant in a given context. In other words, stories are models, and storytellers filter and organize information about complex situations and relationships in ways that are readily absorbed by human cognitive processes. One reason why discourse is so critical in cultural change processes is that it is the means by which we develop a common story, a common model of how and why certain things happen.

\section{IMPLICATIONS FOR NATURAL RESOURCE MANAGEMENT}

The cognitive view of decision making presented above is interesting, but how can we make practical use of it? How can these concepts contribute to design of more effective public policies and management activities?

The most significant insight to be gained by viewing decision making from a cognitive perspective is the crucial importance of discourse, especially under conditions of uncertainty and change. Discourse is an important means by which modification of individual and collective schemas occurs, and so fostering constructive discourse is an essential strategy for addressing complex problems.

The importance of discourse supports the view that collaborative approaches are needed to effectively deal with environmental problems and natural resource management challenges. Collaboration and public participation in at least some stages of decision making have become major themes in governance processes since the 1970s (Bouwen and Tallieu 2004). Proponents of collaborative 
approaches have argued that such a process is likely to generate mutual understanding and trust among stakeholders rather than animosity and suspicion (Sabatier et al. 2005, Lebel et al. 2006). In addition, the distributed nature of knowledge means that inclusion of a diverse group of people with a wide range of expertise and experiential knowledge is necessary to develop a reasonably accurate overview of the dynamic behavior of a given socialecological system that is useful for addressing a particular problem situation. This finding is consistent with the conclusions of resilience researchers that knowledge diversity is a strength in any system, providing robustness when responding to new challenges (Cohen and Levinthal 1990, Westley 1995, Roux et al. 2006).

Despite the potential value of broad participation and discourse in decision making, "public involvement" has often meant impersonal forms of communication, such as newsletters or meetings at which administrators provide a one-way flow of information in an attempt to "educate" the public. Such strategies are relatively simple and inexpensive to implement, but are generally ineffective (Shindler and Aldred Cheek 1999). As demonstrated by diffusion of innovations and social marketing research, simply providing information about a particular issue (e.g., through educational outreach efforts) often has little or no effect on behavior (Kotler and Zaltman 1971, Andreasen 2006, McKenzie-Mohr and Smith 1999). In fact, additional scientific facts may reinforce value disputes and competing interests (Nelkin 1975, 1995, Collingridge and Reeve 1986, Sarewitz 2004), and more information may lead to more confusion rather than less (van der Colk 1988, Milech and Finucane 1998). Many of these efforts are, in effect, public relations exercises aimed at defusing public resentment rather than genuine efforts to develop adaptive problem-solving processes (Miller 1999). Such exercises are counterproductive, as participants quickly figure out whether or not their input is valued. People learn from experience; every negative experience builds cynicism and distrust, and increases the difficulty in getting people to participate in future forums sponsored by the same agencies and organizations.

An interpersonal culture of trust and pragmatism needs to be established in order for social networks for collaboration and public participation to operate effectively (Bardach 1998). In many problem situations, any effort to address the situation occurs within a context of many years of conflict and miscommunication. Trust is at a minimum during the initial stage of relationship building, and thus the first steps in any intervention process will be the most delicate and difficult ones. Rebuilding trust requires interpersonal skills that tend to be rare among management agency personnel (Shindler and Aldred Cheek 1999) because such skills are seldom considered as priority criteria in hiring and promotion decisions within the agencies. In addition, collaborative engagement requires a sincere and visible commitment of time and resources (Bierle and Konisky 2000, Koontz et al. 2004). Viewed from a cognitive perspective, establishing a working relationship is a change process that involves a reorganization of individual and collective schemas through repeated experience of positive interaction. Thus, trust has to be earned over time, which can occur only if there is a longterm commitment to the process. However, organizations tend to be reluctant to commit to relationship-building activities because they are time intensive, failure may be difficult to avoid, and progress often is difficult to recognize. Few organizations, particularly public sector agencies, feel that they can afford to persist with activities that are not producing visible short-term progress.

Cooperation among agencies, organizations, and stakeholder groups is commonly difficult to achieve even when trust is not an issue because it involves changes in standard routines and behaviors. Established patterns of behavior are habitual, and require little conscious thought. Uncertainty is relatively low because past experience provides good information about other people's reactions and responses, and about localized, short-term results. The incentive structures embedded within organizational cultures and institutions tend to reinforce this resistance to change. Individuals commonly learn (develop schemas that lead to) particular behaviors in response to some set of reinforcing rewards, with any negative consequences tending to be vague and distant in time and/or space. Simply removing negative reinforcers and perverse incentives will seldom be sufficient to foster positive change; people are busy; even simply not having to think about an action can reinforce status quo behavior.

Change processes are unlikely to be initiated except in response to some focusing event or crisis, a particularly frustrating conundrum for decision makers and managers who realize that preventing a 
problem is generally more efficient and effective than trying to fix a problem. Individuals and organizations with responsibility for change processes need to look for and be ready to take advantage of relevant windows of opportunity for learning and innovation following focusing events. For example, Olsson et al. (2004) document a case in which a key steward was able to take advantage of a perceived crisis affecting a valued resource to foster transformative change of watershed management institutions in the lower Helgeå River catchment of Sweden. Such openings tend to be short lived; a problem "leaps into prominence [on the agenda], remains there for a short time, and then, though still largely unresolved, gradually fades from the center of public attention" (Downs 1972; p. 38). Obviously, there is no way to predict exactly what will happen, and when and where it will occur, but it is possible to identify types of events that are likely to occur and develop general strategies that can be elaborated upon as appropriate. For example, there is no way of knowing where hurricanes will make landfall next hurricane season, but it is nearly certain that one will hit somewhere, providing an opening for a productive discussion about disaster preparedness and disaster management activities.

An extensive literature, much of which has been published in this journal, has proposed resilience management (e.g., Walker et al., 2002 Yorque et al. 2002, Berkes et al. 2003, Adger et al. 2005, Anderies et al. 2006) and adaptive co-management (e.g., Berkes et al. 1991, Gunderson 1999, Olsson and Folke 2001, Olsson et al. 2004, Carlsson and Berkes 2005, Walker et al. 2006) as more effective than current management strategies for addressing complex problems in social-ecological systems. Fundamental elements of these approaches are: an emphasis on fostering social learning and knowledge transfer through increased stakeholder involvement and more integral public participation (e.g., Shindler and Aldred Cheek 1999, Wondolleck and Yaffee 2000, Bouwen and Taillieu 2004, Olsson et al. 2004, Carlsson and Berkes 2005, Folke 2006, Pahl-Wostl 2006, Roux et al. 2006, Lynam et al. 2007); evolving toward more networked organizational structures through development of linkages among governance organizations (e.g., Schneider et al. 2003, Ivey et al. 2004, Folke 2006); and building trust among individuals and organizations through many interactions over a long time period (e.g., Bardach 1998, Olsson et al. 2004, Sabatier et al. 2005, Lebel et al. 2006). The cognitive view of decision making described in this paper is supportive of these new approaches, and provides a theoretical explanation for the importance of these three key elements. Olsson et al. (2006) observe that successful transformations toward adaptive governance seem to be preceded by the emergence of informal networks that help to facilitate information flows, identify knowledge gaps, and create nodes of expertise. The cognitive processes described in this paper suggest why discourse during social interactions is necessary for the evolution and growth of these vital social networks. This work expands on the proposition put forth by Walker et al. (2006) that mental models drive change in social-ecological systems, and adaptability is enhanced through partially overlapping mental models of system structure and function.

\section{CONCLUSIONS}

As we search for ways to deal with serious societal problems, we need to find ways to take advantage of the human brain's extraordinary ability to deal with complexity and uncertainty. The human brain is a complex adaptive system that is embedded within a broader-scale social-ecological system. Biophysical and social processes occurring at a range of temporal and spatial scales contribute to the emergence of problematic sets of conditions. Human cognition and decision making are also multi-scale processes, with some processing occurring within individual brains, and some occurring through interactions among many brains -collective cognition.

There has been a tendency among researchers, particularly in the decision sciences and economics, to view humans as poor decision makers who, at best, are boundedly rational. However, given the complexity of social-ecological systems and the evolutionary challenges that shaped human cognition, this limited view of human cognitive capacity is both naive and unhelpful. It is certainly true that we commonly do not choose actions identified as optimal by cost-benefit analyses or computer models, and that the outcomes of our decisions are all too often very different from what we expected or desired. This is an inevitable consequence of complexity; there is no right answer to a complex problem, so every decision will be wrong in some way. The challenge within a dynamic situation with great uncertainty is to make decisions that will provide enough positive results to be worth 
the trouble, while steering clear of significant negative impacts.

The cognition-based view of decision making described in this paper explains why discoursecentered approaches to solving societal problems should be more effective than more traditional ones. In this context, a promising development in adaptive management is the increasing adoption of methods derived from the field of mediation and dispute resolution, such as consensus building (e.g., Susskind et al. 1999), joint fact-finding (e.g., Andrews 2002), participatory decision making (e. g., Innes and Booher 1999, Beirle and Cayford 2003), and other collaborative approaches that stress discourse (Connick and Innes 2003). These efforts demonstrate that well-designed collaborative decision processes can help us take advantage of the distinctly human ability to deal with complexity and uncertainty.

Responses to this article can be read online at: http://www.ecologyandsociety.org/vol12/iss 1/art27/responses/

\section{Acknowledgments:}

The author would like to thank Herman Karl and Sun-Jun Myung for the many discussions over the years that inspired and informed this work. I thank Toddi Steelman, Timothy McKeown, David Kronenfeld, and Lawrence Kuznar for their valuable comments on successive drafts of this paper. Thanks also to two anonymous reviewers and the editors of Ecology and Society for their thoughtful comments and suggestions. Some funding for this work was provided by Duke University.

\section{LITERATURE CITED}

Addleson, M. 1996. Resolving the spirit and substance of organizational learning. Journal of Organizational Change Management 9(1):32-41.

Adger, W. N., T. P. Hughes, C. Folke, S. R. Carpenter, and J. Rockströ. 2005. Socialecological resilience to coastal disasters. Science 309(5737):1036-1039.
Anderies, J. M., B. H. Walker, and A. P. Kinzig. 2006. Fifteen weddings and a funeral: case studies and resilience-based management. Ecology and Society 11(1): 21. [online] URL: http://www.ecolo gyandsociety.org/vol11/iss1/art21/.

Andreasen,A. R. 2006. Social marketing in the $21^{\text {st }}$ century. Sage Publications, Thousand Oaks, California, USA.

Andrews, C. J. 2002. Humble analysis: the practice of joint fact-finding. Praeger Publishers, Westport, Connecticut, USA.

Bardach, E. 1998. Getting agencies to work together: the practice and theory of managerial craftsmanship. Brookings Institution Press. [online] URL: http://brookings.nap.edu/books/0815707975/ $\underline{\text { html/index.html. }}$

Bargh, J. A., and T. L. Chartrand. 1999. The unbearable automaticity of being. American Psychologist 54(7):462-479.

Bauer, P. J. 1996. What do infants recall of their lives? Memory for specific events by one-to-twoyear olds. American Psychologist 51:29-41.

Bechara, A., H. Damasio, D. Tranel, and A. R. Damasio. 2002. Deciding advantageously before knowing the advantageous strategy. Pages 629-632 in J. T. Cacioppo, G. G. Berntson, R. Adolphs, C. S. Carter, R. J. Davidson, M. K. McClintock, B. S. McEwen, M. J. Meaney, D. L. Schacter, E. M. Sternberg, S. S. Suomi, and S. E. Taylor, editors. Foundations in social neuroscience. The MIT Press, Cambridge, Massachusetts, USA.

Becker, M. C. 2004. Organizational routines: a review of the literature. Industrial and Corporate Change 13(4):643-677.

Beierle, T. C., and J. Cayford. 2003. Dispute resolution as a method of public participation. Pages 53-68 in R. O'Leary and L. B. Bingham, editors. The promise and performance of environmental conflict resolution. Resources for the Future, Washington, D.C., USA.

Beierle, T. C., and D. M. Konisky. 2000. Values, conflict, and trust in participatory environmental planning. Journal of Policy Analysis and Management 19(4):587-602. 
Berkes, F., J. Colding, and C. Folke, editors. 2003. Navigating social-ecological systems: building resilience for complexity and change. Cambridge University Press, Cambridge, UK.

Berkes, F., P. J. George, and R. J. Preston. 1991. Co-management: the evolution in theory and practice of the joint administration of living resources. Alternatives 18(2):12-18.

Berntson, G. G. 2006. Reasoning about brains. Pages 1-11 in J. T. Cacioppo, P. S. Visser, and C. L. Pickett, editors. Social neuroscience: people thinking about thinking people. The MIT Press, Cambridge, Massachusetts, USA.

Birkland, T. A. 1997. After disaster: agenda setting, public policy, and focusing events. Georgetown University Press, Washington, D.C., USA.

Blatter, J. 2003. Beyond hierarchies and networks: institutional logics and change in transboundary spaces. Governance 16(4):503-526.

Bouwen, R., and T. Taillieu. 2004. Multi-party collaboration as social learning for interdependence: developing relational knowing for sustainable natural resource management. Journal of Community and Applied Social Psychology 14:137153.

Cahill, L., and J. L. McGaugh. 1998. Mechanisms of emotional arousal and lasting declarative memory. Trends in Neurosciences 21(7):294-299.

Carlsson, L., and F. Berkes. 2005. Comanagement: concepts and methodological implications. Journal of Environmental Management 75:65-76.

Chaiken, S., and Y. Trope, editors. (1999). Dualprocess theories in social psychology. Guilford Press, New York, New York, USA.

Cohen, W. M., and D. A. Levinthal. 1990. Absorptive capacity: a new perspective on learning and innovation. Administrative Science Quarterly 35:128-152.

Collingridge, D., and C. Reeve. 1986. Science speaks to power: the role of experts in policy. St. Martin's Press, New York, New York, USA.
Connick, S., and J. E. Innes. 2003. Outcomes of collaborative water policy making: applying complexity thinking to evaluation. Journal of Environmental Planning and Management 46 (2):177-197.

Dagenbach, D., S. Horst, and T. H. Carr. 1990. Adding new information to semantic memory: how much learning is enough to produce automatic priming? Journal of Experimental Psychchology: Learning, Memory, and Cognition 16(4):581-591.

Dooley, K. L. 1997. A complex adaptive systems model of organization change. Nonlinear Dynamics, Psychology, and Life Sciences 1(1):6997.

Downs, A. 1972. Up and down with ecology: the issue attention cycle. The Public Interest 28:38-50.

Evans, J. St. B. T., D. E. Over, and S. J. Handley. 2003. A theory of hypothetical thinking. Pages 321 in D. Hardman and L. Macchi, editors. Thinking: psychological perspectives on reasoning, judgment and decision making. John Wiley, Chichester, UK.

Fiske, S. T., and S. E. Taylor. 1984. Social cognition. Addison-Wesley, Reading, Massachusetts, USA.

Folke, C. 2006. Resilience: the emergence of a perspective for social-ecological systems analysis. Global Environmental Change 16:253-267.

Gazzaniga, M. S. 2002. Brain and conscious experience. Pages 203-214 in J. T. Cacioppo, G. G. Berntson, R. Adolphs, C. S. Carter, R. J. Davidson, M. K. McClintock, B. S. McEwen, M. J. Meaney, D. L. Schacter, E. M. Sternberg, S. S. Suomi, and S. E. Taylor, editors. Foundations in social neuroscience. The MIT Press, Cambridge, Massachusetts, USA.

Grothmann, T., and A. Patt. 2005. Adaptive capacity and human cognition: the process of individual adaptation to climate change. Global Environmental Change 15:199-213.

Gunderson, L. 1999. Resilience, flexibility and adaptive management-antidotes for spurious certitude? Conservation Ecology 3(1): 7. [online] URL: http://www.ecologyandsociety.org/vol3/iss1/ art7/. 
Harris, S. G. 1994. Organizational culture and individual sensemaking: a schema-based perspective. Organizational Science 5(3):309-321.

Hertwig, R., and P. M. Todd. 2003. More is not always better: the benefits of cognitive limits. Pages 213-231 in D. Ardman and L. Macchi, editors. Thinking: psychological perspectives on reasoning, judgment and decision making. John Wiley, Chichester, UK.

Hutchins, E. 1994. Cognition in the wild. The MIT Press, Cambridge, Massachusetts, USA.

Innes, J. E., and D. E. Booher. 1999. Consensus building and complex adaptive systems: a framework for evaluating collaborative planning. Journal of the American Planning Association 65:412-423.

Ivey, J. L., J. Smithers, R. C. De Loe, and R. D. Kreutzwiser. 2004. Community capacity for adaptation to climate-induced water shortages: linking institutional complexity and local actors. Environmental Management 33(1):36-47.

Jackson, P. M., and L. Stainsby. 2000. Managing public sector networked organizations. Public Money and Management 1:11-16.

Kenrick, D.T., N. P. Li, and J. Butner. 2003. Dynamical evolutionary psychology: individual decision rules and emergent social norms. Psychological Review 110(1):3-28.

Keyton, J. 2005. Communication and organizational culture. Sage Publications, Thousand Oaks, California, USA.

Koontz, T. M., T. A. Steelman, J. Carmin, K. S. Korfmacher, C. Moseley, and C. W. Thomas. 2004. Collaborative environmental management: what roles for government? Resources for the Future, Washington, D.C., USA.

Kotler, P., and G. Zaltman. 1971. Social marketing: an approach to planned social change. Journal of Marketing 35:3-12.

Lal, P., H. Lim-Applegate, and M. Scoccimarro. 2001. The adaptive decision-making process as a tool for integrated natural resource management: focus, attitudes, and approach. Conservation Ecology 5(2):11. [online] URL: http://www.ecolog yandsociety.org/vol5/iss2/art11/.

Lam, A. 2000. Tacit knowledge, organizational learning, societal institutions: an integrated framework. Organization Studies 21(3):487-513.

Lebel, L., J. M. Anderies, B. Campbell, C. Folke, S. Hatfield-Dodds, T. P. Hughes. and J. Wilson. 2006. Governance and the capacity to manage resilience in regional social-ecological systems. Ecology and Society 11(1): 19. [online] URL: http: //www.ecologyandsociety.org/vol11/iss1/art19/.

Loewenstein, G. 2001. The creative destruction of decision research. Journal of Consumer Research 28(3):499-505.

Lynam, T., W. de Jong, D. Sheil, T. Kusumanto, and K. Evans. 2007. A review of tools for incorporating community knowledge, preferences, and values into decision making in natural resources management. Ecology and Society 12(1): 5. [online] URL: http://www.ecologyandsociety.org/vol12/iss1/ $\underline{\operatorname{art5/}}$.

Markus, H., and R. B.Zajonc. 1985. The cognitive perspective in social psychology. Pages 137-230 in G. Lindzey and E. Aronson, editors, The handbook of social psychology. $3^{\text {rd }}$ edition. Random House, New York, New York, USA.

McClelland, J. L. 1998. Complementary learning systems in the brain: a connectionist approach to explicit and implicit cognition and memory. Annals of the New York Academy of Sciences 843:153-178.

McKenzie-Mohr, D., and W. Smith. 1999. Fostering sustainable behavior: an introduction to community-based social marketing. New Society Publishers, Gabriola Island, British Columbia, Canada.

Milech, D., and M. Finucane. 1998. Decision support and behavioral decision theory. Pages 291308 in K. Kirsner, C. Speelman, M. Maybery, A. O'Brien-Malone, M. Anderson, and C. MacLeod, editors. Implicit and explicit mental processes. Lawrence Erlbaum Associates, Mahwah, New Jersey, USA.

Miller, A. 1999. Environmental problem solving: psychosocial barriers to adaptive change. Springer, New York, New York, USA. 
Milner, B., L. R. Squire, and E. R. Kandel. 1998. Cognitive neuroscience and the study of memory. Neuron 20:445-468.

Nelkin, D. 1975. The political impact of technical expertise. Social Studies of Science 5(1):35-54.

Nelkin, D. 1995. Science controversies: the dynamics of public disputes in the United States. Pages 444-456 in E. Jasanoff, G. E. Markle, J. Petersen, and T. Pinch, editors. Handbook of science and technology studies. Sage Publications, Thousand Oaks, California, USA.

Olsson, P., and C. Folke. 2001. Local ecological knowledge and institutional dynamics for ecosystem management: a study of Lake Racken Watershed, Sweden. Ecosystems 4:85-104.

Olsson, P., C. Folke, and T. Hahn. 2004. Socialecological transformation for ecosystem management: the development of adaptive co-management of a wetland landscape in southern Sweden. Ecology and Society 9(4):2. [online] URL: http://www.ecolo gyandsociety.org/vol9/iss4/art2/.

Olsson, P., L. H. Gunderson, S. R. Carpenter, P. Ryan, L. Lebel, C. Folke, and C. S. Holling. 2006. Shooting the rapids: navigating transitions to adaptive governance of social-ecological systems. Ecology and Society 11(1): 18. (online) URL: http: //www.ecologyandsociety.org/vol11/iss1/art18/.

Ostrom, E. 1990. Governing the commons: the evolution of institutions for collective action. $10^{\text {th }}$ edition. Cambridge University Press, Cambridge, UK.

Pahl-Wostl, C. 2006. The importance of social learning in restoring the multifunctionality of rivers and floodplains. Ecology and Society 11(1):10. [online] URL: http://www.ecologyandsociety.org/voll1/ iss1/art10/.

Reisberg, D. 1997. Cognition: exploring the science of the mind. W. W. Norton and Company, Inc., New York, New York, USA.

Rogers, E. M. 2003. Diffusion of Innovations. $5^{\text {th }}$ edition. Free Press, New York, New York, USA.

Roux, D. J., K. H. Rogers, H. C. Biggs, P. J. Ashton, and A. Sergeant. 2006. Bridging the science-management divide: moving from unidirectional knowledge transfer to knowledge interfacing and sharing. Ecology and Society 11(1):4. [online] URL: http://www.ecologyandsociety.org/vol11/iss1/ $\underline{\operatorname{art} 4 / .}$

Sabatier, P. A., W. Focht, M. Lubell, Z. Trachtenberg, A. Vedlitz, and M. Matlock. 2005. Collaborative approaches to watershed management. Pages 3-21 in P. A. Sabatier, W. Focht, M. Lubell, Z. Trachtenberg, A. Vedlitz, and M. Matlock, editors. Swimming upstream: collaborative approaches to watershed management. The MIT Press, Cambridge, Massachusetts, USA.

Sarewitz, D. 2004. How science makes environmental controversies worse. Environmental Science and Policy 7:385-403.

Schneider, M., J. Scholz, M. Lubell, D. Mindruta, and M. Edwardsen. 2003. Building consensual institutions: networks and the National Estuary Program. American Journal of Political Science 47 (1):143-158.

Shindler, B., and K. Aldred Cheek. 1999. Integrating citizens in adaptive management: a prepositional analysis. Conservation Ecology 3(1) 9. [online] URL: http://www.ecologyandsociety.org/ vol3/iss1/art9/.

Siegel, D. J. 2001. Towards an interpersonal neurobiology of the developing mind: attachment relationships, "mindsight," and neural integration. Infant Mental Health Journal 22:67-94.

Sloman, S. A. 1996, The empirical case for two systems of reasoning. Psychological Bulletin 119 (1):3-22.

Smith, E. R., and J. DeCoster. 2000. Dual process models in social and cognitive psychology: conceptual integration and links to underlying memory systems. Personality and Social Psychology Review 4:108-131.

Stone, D. 2002. Policy paradox: the art of political decision making. $2^{\text {nd }}$ edition. W. W. Norton and Co., New York, New York, USA.

Susskind, L., S. McKearnan, and J. ThomasLarner. 1999. The consensus building handbook: a comprehensive guide to reaching agreement. Sage Publications, Thousand Oaks, California, USA. 
Tulving, E., S. Kapur, F. I. M. Craik, M. Moscovitich, and S. Houle. 1994. Hemispheric encoding/retrieval asymmetry in episodic memory: positronic emission tomography findings. Proceedings of the National Academy of Sciences 91:2016-2020.

Tversky, A., and D. Kahneman. 1986. Rational choice and the framing of decisions. The Journal of Business 59(4):S251-S278.

van der Colk, H. 1988. Risky behaviour resulting from bounded rationality. Ergonomics 31(4):48590 .

Walker, B., S. Carpenter, J. Anderies, N. Abel, G. S. Cumming, M. Janssen, L. Lebel, J. Norberg, G. D. Peterson, and R. Pritchard. 2002. Resilience management in social-ecological systems: a working hypothesis for a participatory approach. Conservation Ecology 6(1):14. [online] URL: http: //www.consecol.org/vol6/iss1/art14/.

Walker, B. H., L. H. Gunderson, A. P. Kinzig, C. Folke, S. R. Carpenter, and L. Schultz. 2006. A handful of heuristics and some propositions for understanding resilience in social-ecological systems. Ecology and Society 11(1):13. [online] URL: http://www.ecologyandsociety.org/vol11/iss1/ art13/.

Westley, F. 1995. Governing design: the management of social systems and ecosystem management. Pages 391-427 in L. Gunderson, C. S. Holling, and S. Light, editors. Barriers and bridges to the renewal of ecosystems and institutions. Columbia University Press, New York, New York, USA.

Wondolleck, J., and S. Yaffee. 2000. Building bridges across agency boundaries. Pages 381-396 in K. Kolm and J. Franklin, editors. Creating $a$ forestry for the 21st century: the science of ecosystem management. Island Press, Washington, D.C., USA.

Yaffee, S. L. 1997. Why environmental policy nightmares recur. Conservation Biology 11(2):328337.

Yorque, R., B. Walker, C. S. Holling, L. H. Gunderson, C. Folke, S. R. Carpenter, and W. A. Brock. 2002. Towards an integrative synthesis. Pages 419-438 in L. H. Gunderson and C. S. Holling, editors. Panarchy: understanding transformations in human and natural systems. Island Press, Washington, D.C., USA. 